\title{
Chinese childrens' diabetes status, trends and hardship
}

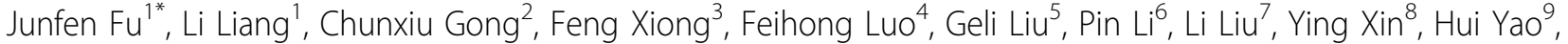 \\ Lanwei Cui ${ }^{10}$, Xing Shi ${ }^{11}$, Yu Yang ${ }^{12}$, Linqi Chen ${ }^{13}$, Haiyan Wei ${ }^{14}$ \\ From 7th APPES Biennial Scientific Meeting \\ Nusa Dua, Bali. 14-17 November 2012
}

Diabetes mellitus is now fast emerging as one of the biggest health catastrophes the world has ever witnessed. It has huge global and societal implications, particularly in developing countries such as China and India [1]. China is now bring with it potential massive increase in type 1 diabetes $(2-5 \%$ per annum increases in incidence in the world's most populous countries) and childhood obesity (with its associated insulin resistance and type 2 diabetes) [2]. A nine-year prospective study on the incidence of childhood type 1 diabetes mellitus in China by the WHO DiaMond Project China Participating Center and Chinese Academy of Preventive Medicine (CAPM) showed that between 1988 and 1996, the overall incidence rate (IR) was 0.59 per 100,000 person-year. The IR was 0.52 / 100,000 (95\% CI: 0.50-0.54) for males and 0.66/100,000 (95\% CI: 0.64-0.68) for females [3]. We recently conducted a nationwide study to evaluate the state and the trend of diabetes based on hospital inpatient data from China's 14 medical centers and pre-diabetes among obese children from October 1995 through September 2010. We found that in the past 15 years, the prevalence of Chinese childhood diabetes increased dramatically and the growth of T2DM has exceeded T1DM. T1DM has occurrence rate of $89.6 \%$ of all diabetes and is still the dominant form of diabetes in children. The prevalence of T1DM was relatively stable from the year of 1995 to 2005, but increased obviously in the recent 5 years according to the hospital records in China. The clear increasing trend from Southwest to East and North disclosed strong regional differences (T1DM from 59.76 to 80.02 and 120.45 , T2DM from 2.52 to 3.77 and $15.64(1 / 100,000)$ (p all $<0.0001)$. Well developed areas had a higher prevalence compared to less developed areas (T1DM: 151.51 vs. 32.2; T2DM:

${ }^{1}$ Children's Hospital of Zhejiang University School of Medicine, Hangzhou, China

Full list of author information is available at the end of the article
15.16 vs. 1.64 and other types: 7.54 vs. $0.42(1 / 100,000)\}$. An important finding in this study is that the prevalence of childhood T2DM in China doubled from 4.1/100,000 in the first 5 years to $10.0 / 100,000$ in the recent 5 years, which was $7.44 \%$ of total diabetics. Though the ratio is still lower than that of America (8\%-46\%)[4] , the trend is clear and the consequences are serious because China has the largest population in the world. Another important finding in this study showed obese children are potential pools of T2DM. Of the 3153 obese children, 18.24\% had IFG alone, $5.99 \%$ had IGT, $4 \%$ had combined IFG and IGT.

\section{Acknowledgements}

This study was supported by the National Key Technology R\&D Program of China (2012BAI02B03) , Zhejiang provincial key disciplines of medicine (Innovation discipline, 11-CX24) and Zhejiang Province key scientific and technological innovation team (2010R50050)

\section{Authors' details}

${ }^{1}$ Children's Hospital of Zhejiang University School of Medicine, Hangzhou, China. ${ }^{2}$ Beijing Children's Hospital of Capital Medical University, Beijing, China. ${ }^{3}$ Children's Hospital of Chongqing Medical University, Yuzhong, Chongqing, China. ${ }^{4}$ Children's Hospital of Shanghai Fudan University, Shanghai, China. ${ }^{5}$ General Hospital of Tianjin Medical University, Tianjin, China. ${ }^{6}$ Children's Hospital of Shanghai, Children's Hospital of Shanghai Jiaotong University, Shanghai, China. ${ }^{7}$ Guangzhou Women and Children's Medical Center, Guangzhou, China. ${ }^{8}$ Shengjing Hospital of China Medical University, Shenyang, China. 'Wuhan Children's Hospital, Wuhan, China. ${ }^{10}$ The First Affiliated Hospital of Harbin Medical University, Harbin, China. ${ }^{11}$ Nanjing Children's Hospital, Nanjing Medical University, Nanjing, China. ${ }^{12}$ Children's Hospital of Jiangxi Province, Jiangxi, China. ${ }^{13}$ Children's Hospital of Soochow University, Jiangsu, China. ${ }^{14}$ Zhengzhou Children's Hospital, Zhenzhou, China.

\section{Published: 3 October 2013}

\section{References}

1. Meetoo D, McGovern P, Safadi R: An epidemiological overview of diabetes across the world. Br J Nurs 2007, 16(16):1002-7.

2. $\quad$ Daneman D: State of the world's children with diabetes. Pediatr Diabetes 2009, 10(2):120-6, Epub 2008 Oct 7. 
3. Li XH, Li TL, Yang Z, Liu ZY, Wei YD, Jin SX, Hong C, Qin RL, Li YQ, Dorman JS, Laporte RE, Wang KA: A nine-year prospective study on the incidence of childhood type 1 diabetes mellitus in China. Biomed Environ Sci 2000, 13(4):263-70.

4. Mohamadi A, Cooke DW: Type 2 diabetes mellitus in children and adolescents. Adolesc Med State Art Rev 2010, 21(1):103-119.

doi:10.1186/1687-9856-2013-S1-013

Cite this article as: Fu et al.: Chinese childrens' diabetes status, trends and hardship. International Journal of Pediatric Endocrinology 2013 2013(Suppl 1):013.

Submit your next manuscript to BioMed Central and take full advantage of:

- Convenient online submission

- Thorough peer review

- No space constraints or color figure charges

- Immediate publication on acceptance

- Inclusion in PubMed, CAS, Scopus and Google Scholar

- Research which is freely available for redistribution

Submit your manuscript at www.biomedcentral.com/submit 